\title{
Gout in black South Africans: a clinical and genetic study
}

\author{
Bilkish Cassim, Girish M Mody, Vijay K Deenadayalu, Michael G Hammond
}

\begin{abstract}
Objective-To define the clinical characteristics of gout and determine if there were any genetic associations with gout in black South Africans.

Methods-The records of 107 patients with gout seen over a five year period were retrospectively analysed. The HLA class I and class II antigens were studied in a prospective survey of 46 patients.

Results-The male to female ratio was $6 \cdot 6: 1$. The diagnosis of gout was based on identification of monosodium urate crystals from the synovial fluid, synovial tissue or tophaceous material in 62 patients $(58 \%)$ and on clinical criteria in the remaining 45 patients $(42 \%)$. The mode of presentation was monoarthritis in 40 patients $(37.4 \%)$, pauciarthritis in $30(28 \%)$ and polyarthritis in $37(34 \cdot 6 \%)$. The joints which were most frequently involved were the knee in 91 patients $(85 \%)$, the first metatarsophalangeal in $80(74 \cdot 8 \%)$ and the ankle in $66(61 \cdot 7 \%)$. A secondary cause was identified in 52 patients $(48 \cdot 6 \%$ ) (diuretic therapy in 48 patients and chronic renal impairment in four); 55 patients $(51.4 \%)$ had primary gout. The genetic study showed an increased frequency of HLA-B14 in patients with primary gout compared with controls.
\end{abstract}

Conclusions-Gout is more common in black Africans than previously recognised and frequently presents with involvement of more than one joint. There was an increased frequency of HLA-B14 in patients with primary gout but the clinical significance of this is uncertain.

(Ann Rheum Dis 1994; 53: 759-762)

Department of Medicine, University of Natal, PO Box 17039 Congella 4013, South Africa B Cassim G M Mody V K Deenadayalu

Transplantation Unit, Natal Institute of Immunology, Durban, South Africa M G Hammond Correspondence to: Dr Cassim.

Accepted for publication 6 July 1994
Genetic and environmental factors influence the prevalence of hyperuricaemia and gout in various ethnic groups ${ }^{1-3}$ and urban and rural populations. ${ }^{45}$ Gout was reported to be uncommon in black Africans ${ }^{6-9}$ and this was confirmed in a previous survey from our hospital. ${ }^{10}$ More recent studies have reported a greater prevalence of gout in black Africans ${ }^{11} 12$ and a higher prevalence has also been reported in a black American population. ${ }^{13}$ Although a genetic predisposition to gout is well recognised, no association with HLA antigens has been reported. ${ }^{14}{ }^{15}$ In view of the relative rarity of gout in black Africans, we studied the HLA class I and class II antigens to determine if these antigens were associated with the development of gout. In addition, we defined the clinical characteristics of gout in black Africans.

\section{Patients and methods}

The King Edward VIII Hospital is a 2000 bed State funded public hospital attached to the University of Natal Medical School in Durban, South Africa. A computer assisted search of the inpatient records over a five year period from 1984 to 1989 was undertaken and the results of synovial fluid analysis were reviewed to identify patients with gout. Patients were considered to have gout if monosodium urate crystals were identified in synovial fluid, synovial tissue or tophi or if they fulfilled the American Rheumatism Association (ARA) clinical criteria for gout. ${ }^{16}$ There were 107 patients who fulfilled these criteria. Their clinical records were reviewed and the age of onset, duration of disease, history of alcohol intake, mode of presentation, criteria for diagnosis, presence or absence of associated diseases and available biochemical data were recorded. The clinical characteristics of the subgroups of patients were compared using Student's $t$ test for equal and unequal variances.

HLA class I and class II antigens were determined in a prospective study of 46 patients with gout. HLA-A, B and C were identified using a two stage lymphocytotoxicity test $^{17}$ and 180 antisera. HLA-DR and DQ were defined with 120 antisera on $B$ cell enriched lymphocyte suspensions prepared by the use of straws packed with nylon wool. ${ }^{18}$ HLA-A, B and $C$ were determined in all 46 patients (23 primary and 23 secondary gout), HLA-DR in 36 patients (20 primary and 16 secondary gout) and HLA-DQ in 34 patients (18 primary and 16 secondary gout). The control group comprised blood donors and staff of the Natal Institute of Immunology. HLA-A, B and C were tested in 2366 controls, HLA-DR in 534 and HLA-DQ in 517. The differences in frequency of the various antigens between patients and controls were tested for significance by means of the $\chi^{2}$ test and Fisher's exact test (in the case of small cell sizes). The resulting probabilities were multiplied by the number of HLA specificities tested to obtain the corrected values.

\section{Results}

The mean age at onset of disease was 50.5 $(11.5)$ years (range $32-85$ years) and the mean 
Table 1 Comparisons between male and female patients

\begin{tabular}{lll}
\hline & $\begin{array}{l}\text { Male } \\
(n=93)\end{array}$ & $\begin{array}{l}\text { Female } \\
(n=14)\end{array}$ \\
\hline $\begin{array}{l}\text { Mean age at onset (yr) } \\
\text { Duration of disease (yr) }\end{array}$ & $49 \cdot 3(12 \cdot 4)$ & $56 \cdot 9(9 \cdot 5)$ \\
Mode of presentation & $3 \cdot 4(4 \cdot 5)$ & $3 \cdot 2(3 \cdot 9)$ \\
$\quad$ Monoarticular (\%) & 38 & 36 \\
$\quad \begin{array}{l}\text { Pauciarticular (\%) } \\
\text { Polyarticular (\%) }\end{array}$ & 28 & 29 \\
Secondary gout(\%) & 32 & 36 \\
Joints involved & 44 & $78 \cdot 6$ \\
$\quad$ Knee (\%) & 87 & 71 \\
$\quad$ Metatarsophalangeal (\%) & 77 & 57 \\
\hline
\end{tabular}

duration of gout was $3.4(4.4)$ years (range one month to 23 years). The male to female ratio was $6 \cdot 6: 1$. Females were significantly older at onset of disease than males ( 57 years compared with 49.3 years $(p<0.01))$ and secondary gout was more frequent in females $(78.6 \%)$ than in males $(44 \%)(p<0.05)$. However, there was no significant difference in the duration of disease, mode of presentation or pattern of joint involvement between males and females (table 1).

The diagnosis of gout was based on identification of monosodium urate crystals in 62 patients $(58 \%)$. The crystals were identified from the synovial fluid in 53 patients, mostly from the knee (43 patients), and from synovial biopsy tissue (three), and tophi (six). A clinical diagnosis of gout was made in the remaining 45 patients $(42 \%)$ who fulfilled the ARA clinical criteria for gout. ${ }^{16} \mathrm{~A}$ history of recurrent acute attacks was obtained in 92 patients $(86 \%)$ and $39(36 \%)$ had suspected tophi. Tophi were present at the elbows in $63 \%$ of patients, ears in $30 \%$, hands in $22 \%$, and feet in $22 \%$. There was no difference in the frequency or site of tophi in patients with primary or secondary gout. Hyperuricaemia at the time of presentation was noted in 103 patients (96\%).

The pattern of presentation was monoarthritis in $40(37.4 \%)$, pauciarthritis in $30(28 \%)$ and polyarthritis in $37(34.6 \%)$. The joints most frequently involved were the knee (91 patients (85\%)), first metatarsophalangeal $(80 \quad(74.8 \%))$ and ankle $(66(61 \cdot 7 \%))$.

A secondary cause was identified in 52 patients $(48.6 \%)-48$ receiving diuretic therapy for either hypertension (43) or cardiomyopathy (five) and four who had chronic renal impairment alone. The four patients with chronic renal impairment included three who were over 60 years and one who was 49 years old. Two of these patients had hypertension alone, one had hypertension and diabetes, and the remaining patient did not have any coexisting disease. Urinary uric acid excretion was normal in the two patients in whom the test was performed. Renal impairment (increased blood concentrations of urea and creatinine) was also present in 14 of the 43 patients with hypertension who were receiving diuretic therapy. The possible contribution of non-steroidal anti-inflammatory drugs (NSAID) to renal impairment could not be determined from a review of the hospital records.

One patient had chronic myeloid leukaemia and another pulmonary tuberculosis; however,
Table 2 Comparisons between primary and secondary gout

\begin{tabular}{lll}
\hline & $\begin{array}{c}\text { Primary } \\
(n=55)\end{array}$ & $\begin{array}{l}\text { Secondary } \\
(n=52)\end{array}$ \\
\hline $\begin{array}{l}\text { Mean age at onset (yr) } \\
\text { Duration of disease (yr) }\end{array}$ & $49 \cdot 3(12 \cdot 3)$ & $57(11 \cdot 4)$ \\
Mode of presentation & $3 \cdot 6(4 \cdot 6)$ & $3 \cdot 2(4 \cdot 3)$ \\
$\quad$ Monoarticular (\%) & 42 & 33 \\
Pauciarticular (\%) & 20 & 36 \\
$\quad$ Polyarticular (\%) & 38 & 31 \\
Male: female & $17 \cdot 3: 1$ & $2 \cdot 7: 1$ \\
Joints involved & & \\
$\quad$ Knee (\%) & 84 & 87 \\
$\quad$ Metatarsophalangeal (\%) & 73 & 77 \\
\hline
\end{tabular}

the diagnosis of gout preceded that of the two other conditions and these patients were classified as having primary gout.

A history of alcohol intake was recorded in 92 patients. Seventy three patients $(79 \%)$ gave a history of alcohol intake, but details as to the type and amount of alcohol consumed were not available.

Table 2 compares patients with primary gout and those with secondary gout. An older age at onset (53 years) was noted in secondary gout, compared with 48.3 years in primary gout $(p=0 \cdot 05)$. Secondary gout was more common in females $(78.6 \%)$ compared with males $(44 \%)(p<0 \cdot 05)$. There was no significant difference in duration of disease, mode of presentation or pattern of joint involvement between the primary and secondary groups.

In the HLA study there was a significant increase in the frequencies of the A28, B14, Cw1, DR8 and DQw3 antigens in patients with primary gout and of A28, B17 and Cw3 antigens in patients with secondary gout compared with control subjects (table 3). After correction for the number of antigens tested, only B14 remained significantly increased in patients with primary gout $(p($ exact $)=0.005)$. Further correction for the two groups of patients also showed a significant increase for B14 $(p<0.01)$. Comparing primary and secondary gout (table 3 ), the B14 antigen was present in $26.1 \%$ of patients with primary gout and $4.4 \%$ of patients with secondary gout $\left(\chi^{2}=4.21 ; \mathrm{p}\right.$ (exact) $\left.=0.048\right)$, whilst the B70 antigen was present in $43 \%$ of patients with secondary gout and $8.7 \%$ of patients with primary gout $\left(\chi^{2}=7 \cdot 22 ; \mathrm{p}(\right.$ exact $\left.)=0.0083\right)$. Corrected $p$ values did not reach statistical significance.

\section{Discussion}

Gout has been recognised as an uncommon disease in black Africans. Small numbers of patients with gout were reported from

Table 3 Comparison of $H L A$ frequencies in control subjects and patients with primary or secondary gout

\begin{tabular}{lcccl}
\hline & $\begin{array}{l}\text { Controls } \\
(n=2366)\end{array}$ & $\begin{array}{l}\text { Primary } \\
(n=23)\end{array}$ & $\begin{array}{l}\text { Secondary } \\
(n=23)\end{array}$ & p(exact) $\dagger$ \\
\hline A28 & $21 \cdot 1$ & $39 \cdot 1^{\star}$ & $43 \cdot 5^{\star \star}$ & \\
B14 & $6 \cdot 1$ & $26 \cdot 1^{\star \star \star}$ & $4 \cdot 4$ & $0 \cdot 048$ \\
B70 & $28 \cdot 1$ & $8 \cdot 7^{\star}$ & $43 \cdot 5$ & $0 \cdot 0083$ \\
Cw1 & $0 \cdot 5$ & $4 \cdot 3^{\star}$ & $0 \cdot 0$ & \\
Cw3 & $12 \cdot 1$ & $13 \cdot 0$ & $30 \cdot 4^{\star \star}$ & \\
DR8 & $4 \cdot 7$ & $15 \cdot 0^{\star}$ & $0 \cdot 0$ & \\
DQw3 & $31 \cdot 9$ & $55 \cdot 6^{\star}$ & $37 \cdot 5$ & \\
\hline
\end{tabular}

Comparisons with control:

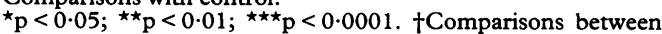
primary and secondary gout. 
Uganda, $^{6}$ Kenya, $^{7}$ Zaire $^{8}$ and Zimbabwe. ${ }^{9}$ During epidemiological surveys in South Africa a few cases of hyperuricaemia were detected but no patients with gout were seen. ${ }^{45}$ Lowental and Dymond ${ }^{19}$ reported 11 patients with gout seen over a 38 month period in Johannesburg and 19 patients with gout who were seen over a five year period were reported from our hospital. ${ }^{10}$ However, a recent study from Brazzaville $^{11}$ showed that gout was the most frequent cause of inflammatory arthritis and was detected in 60 patients, while Mijiyawa et $a l^{12}$ reported 71 patients with gout from Togo. Our study of 107 patients represents the largest series of gout in black Africans and confirms an increasing prevalence, which may be attributable to genetic or environmental factors and to a greater awareness of the disease and increased detection as a result of synovial fluid analysis for monosodium urate crystals in patients with pauciarthritis and polyarthritis. Among the risk factors for gout, a high prevalence of $25 \%$ for hypertension has been reported in our local urban population ${ }^{20}$ and diuretics have constituted baseline therapy.

The mean age of onset was $50.5(11.5)$ years which is older than that found in a British series of 354 patients. ${ }^{21}$ This could be explained by the greater prevalence of secondary gout in our patients. We found a female to male ratio of $6 \cdot 6: 1$ and the age of onset was greater in females, in agreement with findings by Macfarlane and Dieppe. ${ }^{22}$ Secondary gout was present in $48.6 \%$ of our patients, compared with $8.5 \%$ in the British series. ${ }^{21}$ Females were more likely than men to have secondary gout $(78.6 \%$ compared with $44 \%)$. A history of diuretic treatment was obtained in $71.4 \%$ of females and $40 \%$ of males. This compares to the finding of Macfarlane and Dieppe ${ }^{22}$ that all the females and $33 \%$ of males in a group of patients with gout were receiving diuretics. In addition, 14 of their 51 patients with diuretic induced gout had renal impairment which may have been an additional risk factor for the gout. Scott and Higgens ${ }^{23}$ found that all their 15 patients with diuretic induced gout had an additional risk factor, either renal impairment or polycythaemia rubra vera.

Gout secondary to renal disease is rare, ${ }^{24}$ but Vecchio and Emmerson ${ }^{25}$ reported 12 patients with primary renal disease, other than chronic lead nephropathy and polycystic kidneys, at the time of or preceding the first attack of gout. All these patients had a reduced fractional urate clearance which may contribute to the development of hyperuricaemia and gout. A reduced fractional urate clearance has also been reported in a series of 21 patients with precocious familial gout ${ }^{26}$ and 14 patients with hereditary nephropathy with hyperuricaemia and gout. ${ }^{27}$ We found four patients who had gout which could be attributed to primary renal disease. None of these patients had a family history of renal disease or gout and the urinary uric excretion was normal in the two patients in whom the test was performed. The possible contribution of NSAIDs to renal impairment could not, however, be excluded in this retrospective analysis.
The majority of our patients $(62 \cdot 6 \%)$ presented with involvement of more than one joint compared with only $11 \%$ of patients in the British series. ${ }^{21}$ This may be explained in part by the inclusion of outpatients in the British series, whereas we studied mainly hospital inpatients who are likely to have more severe disease; also, older female patients were included in our series. Lawry et $a l^{28}$ reported that polyarticular gout reflected chronicity associated with poor patient understanding, poor patient compliance and suboptimal physician management. In addition, serum concentrations of monosodium urate may be normal in polyarticular gout. ${ }^{29}$ Raddatz et $a l^{30}$ reported that 19 of their 41 patients with polyarticular gout were misdiagnosed initially and we also encountered similar patients.

Previous studies of 66 white patients with gout $^{15}$ and 22 males with gout and 105 of their first degree relatives ${ }^{14}$ did not detect any significant difference in the frequency of HLA compared with controls. We found a significant increase in the frequency of HLA-B14 in patients with primary gout but the clinical significance of this finding is uncertain and may be the result of a sample bias. An increased prevalence of HLA-B14 antigen has also been reported in black South Africans with insulin dependent diabetes ${ }^{31}$ and Graves' disease $^{32}$ but none of our B14 positive patients had either of these diseases.

\section{Conclusions}

In this hospital based study we confirm that gout is more common in black Africans than previously recorded. This may be the result of environmental factors associated with increasing urbanization in a country undergoing socio-economic and political change, genetic factors, or an increased awareness of the disease. On the basis of this study we suggest that, among black Africans, gout must be included in the differential diagnosis of pauciarthritis or polyarthritis in males and postmenopausal females. A weak association with HLA-B14 has been noted in patients with primary gout and further studies are needed to determine if this is of any clinical significance.

1 Rose B S. Gout in the Maoris. Semin Arthritis Rheum 1975;

5: $121-43$.
2 Zimmet P Z, Whitehouse S, Jackson L, Thoma K. High prevalence of hyperuricaemia and gout in an urbanised Micronesian population. BMF 1978; 1: 1237-9.

3 Decker J L, Lane J J, Reynolds W E. Hyperuricaemia in a male Filipino population. Arthritis Rheum 1962; 5: 144-55.

4 Beighton P, Solomon L, Soskolne C L, Sweet B, Robin G. Serum uric acid concentrations in an urbanized South African Negro population. Ann Rheum Dis 1974; 33: $442-5$.

5 Beighton P, Solomon L,Soskolne C L, Sweet B. Serum uric acid concentrations in a rural Tswana community in Southern Africa. Ann Rheum Dis 1973; 32: 346-50.

6 Kibukamusoke J W. Gout in Africans. East Afr Med 1963 40: 354-8.

7 Hall L. Polyarthritis in Nairobi Africans. East Afr Med $\mathcal{f}$ 1963; 45: 378-82.

8 Kayembe D, Sigg-Farner C, Deplaen J L. Gout in an African University hospital. Ann Soc Belg Med Trop 1973; 53: 89-93.

9 Gelfand M. "Medical Arthritis" in African practice. Cent Afr f Med 1969; 15: 131-5. 
10 Mody G M, Naidoo P D. Gout in South African Blacks Ann Rheum Dis 1984; 43: 394-7.

11 Bileckot R, Ntshiba H, Mbongo J A, Sigamong E V, Masson C. Epidemiological and clinical aspects of gout in equatorial Africa. Apropos of 60 cases followed in the Department of Rheumatology of the Teaching Hospital Centre in Brazzaville. Rev Rhum Mal Osteoartic 1991; 58: 863-7. (In French.)

12 Mijiyawa M, Djagnikpo K, Dagbovie K, Agbetra A. Gout in Togolese patients. Rev Rhum Mal Osteoartic 1992; 59: in Togolese patients.

13 Talbott J H, Gottlieb N, Grendelmeier P, Rodriguez E. Gouty arthritis in the Black race. Semin Arthritis Rheum 1975; 4: 209-39.

14 Mituszova M, Judat A, Poor G, Gyodi E, Stenszky V. Clinical and family studies in Hungarian patients with gout. Rheumatol Int 1992; 12: 165-8.

15 Schlosstein L, Terasaki P I, Bluestone R, Pearson C M High association of HLA-A antigen, W27, with
Ankylosing Spondylitis. NEngl 7 Med 1973; 288: 704-6.

16 Wallace S L, Robinson $\mathrm{H}$, Masi A T, Decker J L, McCarty D J, Yu T. Preliminary criteria for the classification of the acute arthritis of primary Gout. Arthritis Rheum 1977; 20: 895-900.

17 Mittal K K, Mickey M R, Singal D P, Terasaki P I. Serotyping for homotransplantation. XVIII. Refinement of microdroplet lymphocyte test. Transplantation 1968; 6:

18 Danilovs J A, Ayoub G, Terasaki P I. Joint report: B lymphocyte isolation by thrombin-nylon wool. In Terasaki P I, ed. Histocompatibility testing 1980 Los Angeles: UCLA Tissue Typing Laboratory, 1980: $287-8$

19 Lowental M N, Dymond I D. Gout and hyperuricaemia in Blacks. S Afr Med f 1977; 51: 969.
20 Seedat $\mathrm{Y} \mathrm{K}$, Seedat M A, Nkomo M N. The prevalence of hypertension in the urban Zulu. S Afr Med F 1978; 53: 923-7.

21 Grahame R, Scott J T. Clinical survey of 354 patients with gout. Ann Rheum Dis 1970; 29: 461-8.

22 Macfarlane D G, Dieppe P A. Diuretic induced gout in elderly women. Br f Rheumatol 1985; 24: 155-7.

23 Scott J T, Higgens C S. Diuretic induced gout: a multifactorial condition. Ann Rheum Dis 1992; 51: 259-61.

24 Sorensen L B. Gout secondary to chronic renal disease: studies on urate metabolism and rheumatic disease. Ann Rheum Dis 1980; 39: 424-30.

25 Vecchio P C, Emmerson B T. Gout due to renal disease. Br f Rheumatol 1992; 31: 63-5.

26 Calabrese G, Simmonds H A, Cameron J S, Davies P M. Precocious familial gout with reduced fractional urate clearance and normal purine enzymes. $Q \mathcal{F} M e d 1990 ; 75$ : 441-50.

27 Puig J G, Miranda M E, Mateos F A, et al. Hereditary nephropathy associated with hyperuricaemia and gout. Arch Intern Med 1993; 153: 357-65.

28 Lawry G V, Fan P T, Bluestone M B. Polyarticular versus monoarticular gout: a prospective analysis of clinical features. Medicine 1988; 67: 335-44. 29 .

Acute pobinson D R Acute polyarticular gout. $A m$ f Med 1974; 56: 715-9.

30 Raddatz D A, Mahowald M L, Bilka T J. Acute polyarticular gout. Ann Rheum Dis 1983; 42: 117-22.

31 Hammond M G, Asmal A C, Omar M A K. HLA and insulin dependent diabetes in South African Negroes. Diabetologia 1980; 19: 101-2

32 Omar M A K, Hammond M G, Desai R K, Motala A A Abboo N, Seedat M A. HLA Class I and II antigens in South African Blacks with Graves' disease. Clin Imm Immunopath 1990; 54: 98. 